\title{
Vantagens e problemas da introdução de peixes alienígenas na piscicultura do Brasil
}

\author{
Hitoshi Nomura \\ Faculdade de Fil. Cienc. Letras de Ribeirão Preto \\ Universidade de S. Paulo
}

Desde fins do sécuío passado, várias espécies de peixes alienígenas foram introduzidas no Brasil, algumas com sucesso, a saber: carpa, Cyprinus carpio, em 1882; truta arco-íris, Salmo gairdnerii, em 1913, 1949 e 1950; truta, Salmo fario, em 1913; black-bass, Micropterus salmoides, em 1922, peixe-rei, Basilichthys bonariensis, em 1930 e 1935; blue-gill, Lepomis macrochirus, em 1922; tilápias, Tilapia rendalli, em 1953; Tilapia hornorum e Tilapia nilotlca, em 1971.

Rodolpho von lhering - o pai da piscicultura brasileira - era visceralmente contrário à disseminação da carpa, visto os desastres por ela causados nos Estados Unidos. Por isso, interessou-se em resolver o problema da fecundação artificial dos nossos peixes de piracema, solucionado com o método da hipofisação, hoje aplicado rotineiramente, tanto no Ceará quanto em muitas partes do mundo.

A carpa deu início à piscicultura no Brasil, tendo sido introduzida no Rio de Janeiro em 1882 (Godoy, 1965a). Em São Paulo começou a ser cultivada por particulares alemães, em 1893, mas oficialmente só foi introduzida em 1904 (Azevedo, 1972). Em 1934, o então Departamento de Indústria Animal, da Secretaria da Agricultura de São Paulo, iniciou sua criação na subestação de Pindamonhangaba. Em 1939 havia cerca de 40 criadores no Vale do Paraíba (Anônimo, 1939).

A carpa é criada exclusivamente com fins comerciais, não servindo para o povoamento de rios nem p̄ara a pesca esportiva. Em São Paulo, o seu consumo chega a 100 toneladas métricas anuais, sendo a espécie preferida pe- los nipônicos e israelitas, não sendo apreciada pelos brasileiros. Na Fazenda Setúbal, a $7 \mathrm{~km}$ de Mairinque, SP, há uma criação semi-intensiva, onde ela atinge 700 a 800 gramas em três anos (Castro, 1965).

Sua criação em tanques-rede, muito comum no Japão, foi tentada em Jaboticabal, SP. Foram utilizados 470 alevinos, correspondendo a uma densidade de 42 deixes por metro quadrado, alimentados duas vezes por dia. Em dois meses, os alevinos, de 9,2 gramas e 91 $\mathrm{mm}$, atingiram 57 gramas e $124 \mathrm{~mm}$, com ganho de peso da ordem de $620 \%$ (Castagnolli, Millen \& Mendonça Netto, 1971).

A sua presença no rio Paraíba é mínima, não tendo até hoje afetado a fauna ictiológica local, contrariando a opinião original de lhering. É espécie rústica, que se cria muito bem em pequenas represas ou tanques.

As tentativas iniciais de introdução da truta, Salmo fario, e da variedade arco-íris, Salmo gairdnerii, não foram bem sucedidas no Rio de Janeiro em 1913 (Moreira, 1919). Em 1949, foram trazidos 5.000 ovos embrionados da Dinamarca, mas uma enchente de grandes proporções exterminou os 2.500 sobreviventes, em Campos do Jordão, SP. Em maio de 1950 chegaram mais 50.000 ovos de Esbjerg, Dinamarca, que foram introduzidos nos rios da Serra da Bocaina (Faria, 1953a, b). As condições físico-químicas de suas águas já tinham sido examinadas e mostraram-se adequadas para a aclimatação da espécie (Azevedo, 1953). Mais tarde, outros rios da região, assim como os rios Bonito e Funil, foram povoados com a truta arco-íris (Azevedo, Vaz \& Parreira, 1961), atraindo muitos turistas para a região. Sua fecundação artificial foi conseguida com 
sucesso em 1974, tanto no terreno oficial (Castro, 1974; Stempniewski \& Godinho, 1976), quanto no particular (Castro, 1975). O tempo de incubação varia de 23 a 30 dias, à temperatura média de $10^{\circ} \mathrm{C}$.

O black-bass, Micropterus salmoides, foi introduzido em Belo Horizonte, MG, em 1922 (Godoy, 1965b), sendo hoje encontrado em numerosos açudes mineiros e paulistas, assim como no Rio de Janeiro e Paraná, não se tendo notícias de que tenha causado transtornos aos peixes nacionais, sendo espécie de fácil criação. Atinge 2.600 gramas e $55 \mathrm{~cm}$ em cinco anos (Godoy, 1965b).

Em 1930 (Ihering, 1930) e 1935 (Azevedo, 1935) foi tentada a introdução do peixe-rei argentino, Basilichthys bonariensis, mas ambas as tentatvias fracassaram. $O$ encontro da espécie em estado nativo no Rio Grande do Sul resolveu o problema, sendo ela criada em território gaúcho com grande sucesso (Kleerekoper, 1945).

O blue-gill, Lepomis macrochirus, é apenas criado em pequena escala nas Estações de Piscicultura de Pirassununga, SP e do $\mathrm{Km}$ 47 da Rodovia Rio-São Paulo (Silva, 1962). Foi introduzido em Belo Horizonte em 1922.

A introdução de dois ciclídeos da bacia amazônica, o tucunaré, Cichla ocellaris, e o apaiari, Astronotus ocelatus, não foi bem sucedida em certas partes do sul do País, fazendo com que Azevedo (1955) resolvesse importar a Tilapia rendalli do Congo em 1953. Hoje tal espécie está disseminada em grande parte do território nacional, mas sua criação não é orientada, principalmente no Sul. Por isso, nota-se sempre um superpovoamento dos lagos ou represas onde ela foi introduzida, causado pela sua alta capacidade reprodutiva: quatro vezes por ano e 2000 a 6000 óvulos por fêmea. O segredo da tilapiacultura reside na separação dos exemplares por sexos e sua criação em separado, mas isso não vem sendo feito com essa espécie. Por causa disso, o Departamento Nacional de Obras Contra as Secas - DNOCS, resolveu importar mais duas espécies em 1971: a Tilapia hornorum e a Tila- pia nilotica, O cruzamento do macho da primeira com a fêmea da segunda espécie produz 100\% machos híbridos (Lovshin, Silva \& Fernandes, 1974), bastando engordá-los, não ocorrendo o problema do superpovoamento. Em criações experimentais já se conseguiu a produção de 600 quilos por hectare/ano de híbridos com 300 gramas, utilizando-se alevinos de 20 gramas, alimentados com subprodutos da agricultura. Outros métodos de controlar a reprodução são: uso de predadores de tilápias jovens; reversão sexual por tratamento hormonal; eliminação da capacidade reprodutiva, usando esterilizantes químicos ou irradiação das gônadas.

A Tilapia rendalli foi colocada em 52 açudes do nordeste, sendo que 15 desses produziram volume considerável; a Tilapia nilotica foi introduzida em 39 açúdes, sendo que apenas 2 mostraram produção comercial (Lovshin, Peixoto \& Vasconcelos, 1975). O peso da primeira espécie chegou a variar de 160 a 400 gramas. A produção total de peixes nos açudes controlados pelo DNOCS foi de 12.000 toneladas métricas em 1974, no valor de Cr\$ 32.743.375,00 e, desse total, 761 toneladas eram representadas pelas tilápias $(6 \%)$, valendo $\mathrm{Cr} \$ 2.179 .141,00$. As tilápias ocuparam o quinto lugar na produção em peso dos açudes sob a aáministração do DNOCS, vindo em primeiro lugar a pescada do Piauí. Plagioscion squamosissimus, seguida da curimatâ comum, Prochilodus argenteus, traíra, Hoplias malabaricus, e tucunaré, Cichla ocellaris.

Um açude particular de 0,8 hectare foi povoado com tilápias híbridas. O seu peso médio era de 36 gramas. Após 207 dias foram capturados $1.975 \mathrm{~kg}$, com peso médio de 266 gramas, equivalendo a uma produção de 4.233 $\mathrm{kg}$ por ha/ano. O criador vendeu os peixes vivos a um intermediário por $\operatorname{Cr} \$ 7,00 \circ \mathrm{kg}$, lucrando Cr\$ $3.146,00$ ou Cr\$ $6.741,00$ por ha/ano (Jensen, 1975).

Em 1975, foram distribuídos 38.000 alevinos de híbridos de tilápias aos fazendeiros e espera-se que a produção por hectare seja compensadora. O clima e a qualidade das águas nordestinas oferecem condições exce- 
lentes para o rápido crescimento das tilápias. As populações dessa espécie são controladas porque a maior parte das outras espécies é predadora; contribui também para esse controle a constante pesca exercida pelos pescadores profissionais.

Além do tucunaré, do apaiari, da pescada do Piauí, já criadas com sucesso principalmente no nordeste, temos muitas outras espécies que merecem ser criadas artificialmente, como o mandi, Pimelodus clarias. Um passo nesse sentido foi dado recentemente na Estação de Piscicultura de Furnas, MG, com a criação artificial do dourado, Salminus maxillosus (Anônimo, 1976). Aliás, esta espécie já foi artificialmente fecundada em 1944-1945, na Estação Experimental de Biologia e Piscicultura de Pirassununga, SP (Morais Filho \& Schubart, 1955), e 500 dos alevinos então obtidos foram introduzidos no rio Paraíba, que até aquela data não possuía tal espécie (Azevedo, 1954).

As espécies exóticas mencionadas não têm causado problemas aos peixes nacionais, mas há indícios de que a Tilapia rendalli, à falta de outros alimentos, vem-se nutrindo da desova de pequenas espécies, tal como os lambaris, Astyanax spp.

\section{BIBLIOGRAFIA CITADA}

ANÔNIMO

1939 - A piscicultura no Vale do Paraíba. O Estado de São Paulo, edição de 19 de fevereiro.

1976 - O nosso dourado será salvo pela tecno. logia. Folha de S. Paulo, 56(17.197) : 17, ediçẩo de 12 de abril.

AZEvedo, $P$.

1935 - Introdução do peixe-rei no Brasil. O Campo, fev. : 25-30.

1953 - A aclimação da truta em águas paulistas. Geografia, (3) : 17-20.

1954 - Aclimação do dourado no rio Paraíba. Notas Agrícolas, 9 : 244-245.

1955 - Aclimação da tilápia no Brasil. Cháca ras e Quintais, 92(2) : 190-192.
1972 - A piscicultura, histórico, consideraçōes gerais e perspectivas futuras. In: Po. luição e piscicultura. São Paulo, Fac. Saúde Públ. da USP e Inst. Pesca. p. 177-180.

AzeVedo, P.; VAz, J.O. \& Parreira, W.B.

1961 - Aclimação da truta arco-íris em algumas águas de São Paulo. Bol. Ind. Anim., n.s., 19 : 75-105.

Castagnolli, N.; Millen, E. \& Mendonça Netro, A.T.

1971 - Criação em confinamento da carpa comum, Cyprinus carpio Linnaeus, 1758 em tanques-rede. Ciência e cultura. 23 (supl.) : 278.

CAstro, J.B.

1965 - Criação de carpa para venda do peixe vivo. Suplemento agrícola, $O$ Estado de S. Paulo, 11(527): 8-9, edição de 19 de maio.

1974 - Fertilização artificial de óvulos de trutas. Suplemento agrícola, O Estado de S. Paulo, 20(1003) : 8-10, ediçāo de 18 de setembro.

1975 - Como se cria a truta, um peixe sofisticado. Suplemento agrícola, o Estado de S. Paulo, 21(1033): 8-10, ediçẫo de 16 de março.

FARIA, A.

1953a - Notas sobre a biologia da truta "Arco-fris" - Salmo gardinierii irideus (Gibbons) - importada da Dinamarca e introduzida em rios do Sertão da Bocaina, municipio de Bananal, Estado de S. Paulo. In: Dados sobre a biologia da truta arco-íris. Rio de Janeiro, Div. de Caça e Pesca. p. 31-36.

1953b - O atual desenvolvimento da criação de trutas na Serra da Bocaina. In: Dados sobre a biologia da truta arco-íris. Rio de Janeiro, Divisão de Caça e Pesca. p. 37-39.

Godoy, M.P.

1965a - Carpas e tilápias. Chácaras e quintals, 111(2) : 177-180.

1965b - Criação de Peixe. 3. ed rev. e aum. Pirassununga, Estação Exp. de, Biologia e Piscicultura.

IHERING, $R$. VON

1930 - Dados sobre a pesca e o peixe no rio da Prata. Bol. Agric., 31 (11/12) : 1242-1264. 
JENSEN, J.W.

1975 - Report on the intensive culture of the tilapia hybrid on a private farm in Northeast Brazil. Notes et Documents, Centre Technique Forestier Tropical, Février : 27-29.

KLEEREKOPER, $\mathrm{H}$

1945 - O Peixe-Rei. Rio de Janeiro, Serv. de Inform. agrícola. $98 \mathrm{p}$.

Lovshin, L.L.; PeIxoto, J.T. \& VAsconcelos, E.A.

1975 - Tilapia sp. in the northeast of Brazil; economic and ecological considerations. Encontro sobre Limnologia, Piscicultura e Pesca continental: situação Nacional de perspectivas para o Estado de Minas Gerais. 13 p.

Lovshin, L.L.; SILVA, A.B. \& FERNANDES, J.A.

1974 - The intensive culture of the all-male hybrid of Tilapia hornorum (male) $x$ Tilapia nilotica (female) in Northeast Brazil. FAO/CARPAS Symposium on Aquaculture in Latin America, SE, $22: 1-18$.
Morais Filho, M.B. \& SCHUbart, O.

1955 - Contribuição ao estudo do dourado (Salminus maxillosus Val,) do rio Mogi Guassu (Pisces, Characidae). São Pau1o, Divisão de Caça e Pesca. 131 p.

MOREIRA, C

1919 - Recherches sur la reproduction de l'Hoplias malabaricus (Bloch) et sur l'Incabation d'Oeufs de Salmo fario au Brésil. Bull. Soc. Zool. France, 45: 329-336.

SILVA, S.L.O.

1962 - Sobre a desova dos peixes criados no Posto Experimental de Biologia e Piscicultura do $\mathrm{Km}$ 47. Arq. Mus. Nac., 52 : 213-218.

STEMPNIEWSKI, H.L. \& GODINHO, H.M.

1976 - Fecundação artificial de trutas arco-íris, Salmo irideus Gibbons, Ciência e Cultura, 28 (7-supl.) : 435 . 